\title{
INCIDENCE OF RETINOPATHY CHANGES IN THE NEWLY DETECTED CASES OF TYPE-2 DIABETES MELLITUS
}

\author{
Kandasamy Kavitha1, Sundaresan Uma Maheswari²
}

${ }_{1}^{1}$ Assistant Professor, Department of Ophthalmology, Government Mohan Kumaramangalam Medical College, Salem, Tamilnadu. ${ }^{2}$ Assistant Professor, Department of Ophthalmology, Government Mohan Kumaramangalam Medical College, Salem, Tamilnadu.

ABSTRACT
BACKGROUND
DR is due to microangiopathy affecting the retinal precapillary arterioles, capillaries and venules. Vision loss from diabetes is
essentially preventable with timely detection. Detection of the earliest signs of DR is an essential requirement of diabetes care
leading to early preventive and treatment strategies, which can arrest progression of serious consequence of diabetes. Glycaemic
control and strict control of hypertension have a clear effect on the development of the microvascular complications of diabetes.

\section{MATERIALS AND METHODS}

200 patients who were diagnosed as new cases of DM type II were taken up in this study. The patients were randomly selected.

Diagnostic Criteria:

- $\quad$ Fasting blood sugar- $126 \mathrm{mg} / \mathrm{dL}$.

- $\quad$ Post prandial blood sugar- If glucose level is higher than $200 \mathrm{mg} / \mathrm{dL}$ after $2 \mathrm{hrs}$.

\section{RESULTS}

- $\quad$ The predominantly affected group was aged between 40 and 50 years (42.5\%).

- $\quad$ The male: female ratio was 2.1: 1 .

- $\quad$ The majority of patients had visual acuity between $6 / 9$ and $6 / 18$ on first presentation (43.5\%).

- $12 \%$ of patients had positive family history.

- $\quad 33 \%$ of the patients were exposed to risk factors like smoking, alcohol and anaemia.

- $12 \%$ of the patients had bilateral diabetic retinopathy.

- $\quad$ Of the 400 eyes evaluated 62 eyes had NPDR and 2 had PDR, while 336 had no features of diabetic retinopathy.

- $\quad$ Among the NPDR, majority (38 eyes) fell under moderate NPDR.

- One patient had vitreous haemorrhage at the time of presentation.

\section{CONCLUSION}

- Incidence of DR is common among middle-aged working population.

- Both eyes were usually affected, though asymmetrically.

- In conclusion DR including sight threatening complications was found even at the time of diagnosis of diabetes mellitus type II.

- Early diagnosis and treatment of DR helps to stabilise the visual acuity and prevent further vision loss.

- Diagnosis of complications of diabetic retinopathy at the earliest helps to control progression of proliferative diabetic retinopathy.

- Increased awareness of the ophthalmological complication in diabetes is necessary in the society to prevent unnecessary visual morbidity in diabetic patients.

\section{KEYWORDS}

DM- Diabetes Mellitus, DR- Diabetic Retinopathy, NPDR- Non-Proliferative Diabetic Retinopathy, PDR- Proliferative Diabetic Retinopathy.

HOW TO CITE THIS ARTICLE: Kavitha K, Maheswari SU. Incidence of retinopathy changes in the newly detected cases of type-2 diabetes mellitus. J. Evolution Med. Dent. Sci. 2018;7(17):2104-2107, DOI: 10.14260/jemds/2018/471

\section{BACKGROUND}

Diabetes mellitus is a type of metabolic disease characterised by hyperglycaemia resulting from defects in insulin secretion, defects in insulin action or both. Raised

'Financial or Other Competing Interest': None.

Submission 15-03-2018, Peer Review 08-04-2018,

Acceptance 14-04-2018, Published 23-04-2018.

Corresponding Author:

Sundaresan Uma Maheswari,

Department of Ophthalmology,

Government Mohan Kumaramangalam Medical College,

Salem, Tamilnadu.

E-mail: umagirihari@gmail.com

DOI: $10.14260 /$ jemds $/ 2018 / 471$

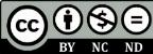

blood sugar levels produce classical symptoms like polyuria, polydipsia and polyphagia. There are three main types of diabetes mellitus: Type 1- IDDM is an autoimmune disease due to which the immune system of one's own body attacks and destroys the insulin-producing cells of the pancreas. In Type 2- NIDDM- Resistance to insulin causes cells not to respond to secreted insulin along with a probable association with an absolute insulin deficiency. Another is Gestational Diabetes. Long-term complications are usually high, usually manifest 10 to 20 years later, although it may be the presenting feature in a few patients. Damage to the vascular system is the main reason for development of complications. Diabetes damages the small calibre vessels like capillaries. DR is caused by damage to blood vessels of the light sensitive 
tissue at the retina causing formation of new blood vessels in the retina, thus producing symptoms of decreased visual acuity and sometimes potential blindness. The symptoms of DR vary from blurry vision, fluctuating vision, impaired colour vision, vision loss and even blindness and in many patients the condition was even symptomless.

Ocular manifestations of diabetes involving eyelids which include Xanthelasma, recurrent stye, internal hordeolum, chalazion, in the cornea DM causes pigment dispersal at back of cornea, decreased corneal sensations, punctate keratopathy, Descemet's folds, higher incidence of infective corneal ulcer, in conjunctiva DM causes telangiectasia, sludging of the blood in conjunctival vessels, subconjunctival haemorrhage, in iris DM causes rubeosis iridis, in lens DM leads to snow-flake cataract, posterior subcapsular cataract, in vitreous DM causes vitreous haemorrhage and fibrovascular proliferation secondary to diabetic retinopathy, posterior vitreous detachment, asteroid bodies, diabetic retinopathy, lipaemia retinalis, decreased contrast sensitivity and colour vision, in optic nerve DM leads to POAG, neovascular glaucoma, hypotony, optic neuritis, anterior ischaemic optic neuropathy, optic atrophy, and in extraocular muscles DM causes extraocular ophthalmoplegia and causes changes in refraction like hypermetropic shift in hypoglycaemia, myopic shift in hyperglycaemia and decreased accommodation.

\section{Diabetic Retinopathy}

DR is due to microangiopathy affecting the retinal precapillary arterioles, capillaries and venules. Vision loss from diabetes are essentially preventable with timely detection. Detection of the earliest signs of DR is an essential requirement of diabetic care leading to early prevention and treatment strategies, which can arrest progression of serious consequence of diabetes. Glycaemic control and strict control of hypertension have a clear effect on the development of the microvascular complications of diabetes. The development of microvascular complications in diabetes depends on the level of control of blood glucose and blood pressure. Some facts on diabetic retinopathy are $85 \%$ to $90 \%$ of cases of diabetes mellitus eventually develops DR (WESDR). It is the leading cause of blindness in working age group worldwide[1] and timely treatment can prevent upto $60 \%$ to $70 \%$ of visual loss. According to latest WHO report, India has 31.7 million diabetic subjects currently. This number is expected to increase to 79.4 million by 2030 . The incidence of diabetes in Indians varies from that of Europeans by having a younger age of onset,[2] obesity being less ${ }^{[3]}$ and stronger genetic association. ${ }^{[4]}$ These differences and the increased prevalence of the disease in India indicate the need for more diabetic based studies.[5]

\section{Epidemiology}

Diabetic Retinopathy has been one of the foremost cause of blindness in the working age group of both developed and developing countries. In Indians, it is the sixth cause of blindness. At present, the prevalence of diabetic retinopathy is increasing day by day with increase of diabetes in India. The diabetic retinopathy is highly specific vascular complication of both type I and type II diabetes. Systemic risk factors include longer duration of diabetes,[6] severity of diabetes,[7] high systolic blood pressure,[8] pregnancy,[9] patients on insulin treatment, nephropathy, hyperlipidaemia,[10] smoking, anaemia[11] and alcoholism.[12] In glaucoma, there is reduced metabolic activity and reduced vascular perfusion. This ultimately protects from development of DR. Unilateral carotid artery stenosis protects the ipsilateral eye from development of DR. High myopes with choroidal degeneration patients are protective against DR due to reduced retinal metabolism. Cataract removal exaggerate the progression of NPDR and already existing DME and lead onto the development of rubeosis.

\section{Aims and Objectives}

To find out the incidence of retinopathy changes in first time detected new cases of type II diabetes mellitus.

\section{MATERIALS AND METHODS}

It was a cross-sectional study conducted over a period of 1 year from 2014 to 2015. Among 400 eyes, 200 patients were diagnosed as new case of type II Diabetes mellitus attending the Outpatient Department of Ophthalmology in Govt. Mohan Kumaramangalam Medical College Hospital, Salem. Both male and female patients of age group between 30 - 60 years were taken up in this study. The patients were selected nonrandomly and the sample was taken for convenience. Type I diabetes mellitus, chronic renal failure, pregnant women, patients with opaque media and patients who did not give consent for the study were excluded from our analysis. Special emphasis was laid in categorising age, sex incidence, presence of DR, staging of DR, presentation of complications and associated comorbid conditions. Diagnostic criteria include fasting blood sugar more than $126 \mathrm{mg} / \mathrm{dL}$ and post prandial blood sugar - higher than $200 \mathrm{mg} / \mathrm{dL}$ after $2 \mathrm{hrs}$.

Data collection was done using a case study proforma by principal investigator. After obtaining informed consent from all patients a detailed evaluation including ocular history, best corrected visual acuity, slit lamp examination of anterior segment, posterior segment examination with indirect ophthalmoscope, slit lamp biomicroscopy with 90D, intraocular pressure measured with Goldmann applanation tonometer, gonioscopy, visual field analysis and fundus fluorescein angiography for selective cases were done.

\section{RESULTS}

In our study number of male patients participated were 136 and female were 64. Regarding age, 61 patients belonged to 30 - 40 years, 85 patients belonged to 41 - 50 years and 54 patients belonged to 51 - 60 years. Least incidence was seen in patients in age group 50 to 60 years, because they had undergone previous blood sugar evaluations for various purposes. Hence, their diabetic status was detected earlier. Among 200 patients evaluated, 162 patients were diagnosed to have DR. Among them, family history of diabetes was positive for 89 patients. In our study many patients had associated risk factors like smoking 56 patients, alcoholic 61 patients, anaemia 8 patients, smoking with alcoholism 12 patients and smoking alcoholism with anaemia were 47 patients. These 324 patients had various stages of DR including PDR. Our study showed raised intraocular pressure for 36 patients, of them gonioscopic examination with Goldmann single mirror lens the angles were open for them. In our study 36 patients had bilateral DR with asymmetrical DR, while 126 of them had unilateral eye involvement. On 
evaluating the visual acuity on first time presentation, 184 eyes had $6 / 6$ vision. 174 patients had visual acuity between $6 / 9$ and $6 / 18$ and 42 patients had visual acuity between $6 / 24$ and $6 / 60$. The reduction in vision is due to various other causes like refractive error, cataract, pseudophakia with posterior capsular opacification, age related macular disorder changes and other retinal pathologies. Regarding the type of retinopathy in our study 292 eyes had NPDR and 32 eyes had PDR, of them 18 eyes had neovascularisation of disc and other 8 had neovascularisation elsewhere and 9 eyes had vitreous haemorrhage. 135 patients fell into the category of moderate NPDR, 89 patients had mild NPDR, 42 patients had severe NPDR and 26 had very severe NPDR. Of the DR patients 5 patients had vitreous haemorrhage, is one of the sight threatening complication seen on initial presentation. In our study, the HbA1C levels of the patients with DR are higher than those of the patients without retinopathy changes. So this indicates that patients might have had poor glycaemic control prior to the development of DR.

\begin{tabular}{|c|c|c|}
\hline $\begin{array}{c}\text { Age of Onset } \\
\text { of DM }\end{array}$ & $\begin{array}{c}\text { Recommended Time of } \\
\text { First Eye Examination }\end{array}$ & $\begin{array}{c}\text { Routine Minimum } \\
\text { Follow-up }\end{array}$ \\
\hline $0-30$ & $\begin{array}{c}\text { Within five years of } \\
\text { diagnosis }\end{array}$ & Annually \\
\hline 31 or Older & Upon diagnosis & Annually \\
\hline Pregnancy & $\begin{array}{c}\text { Before conception or } \\
\text { early in first trimester }\end{array}$ & $\begin{array}{c}\text { Every 3 months or } \\
\text { at the discretion of } \\
\text { the ophthalmologist }\end{array}$ \\
\hline
\end{tabular}

Table 1. Suggested Timetables for Detailed Ophthalmologic Examination of Diabetic Patients

\begin{tabular}{|c|c|}
\hline Retinal Abnormality & Suggested Follow-Up \\
\hline $\begin{array}{c}\text { Normal or rare } \\
\text { microaneurysms }\end{array}$ & Annually \\
\hline Mild NPDR & Every 9 months \\
\hline Moderate NPDR & Every 6 months \\
\hline Severe NPDR & Every 2-4 Months \\
\hline CSME & $\begin{array}{c}\text { Every 2-4 months (Consider laser } \\
\text { therapy) }\end{array}$ \\
\hline PDR & $\begin{array}{c}\text { Every 2-3 months (Consider laser } \\
\text { therapy) }\end{array}$ \\
\hline Table 2. Suggested Timetables for Follow-Up in Diabetic \\
Retinopathy Patients
\end{tabular}

\section{DISCUSSION}

The aim of the study was to find the incidence of retinopathy changes in first time detected DM type II. Our observation were compared with various other studies about diabetic retinopathy. Various studies performed in India has found that there is an increased prevalence of DR in type II DM in the past 30 years. DR prevalence in newly diagnosed subjects in our study was $81 \%$. But it is comparatively higher than the prevalence data found in Europe study, which was $20 \%$ to $35 \%$. The ratio of male-to-female patients in this study was 2.1: 1 , while it was 1.5: 1 in the Wisconsin epidemiological study of DR 1984 and 1.8: 1 in the Oman study. In our study DR was more common in men, further studies such as UKPDS study, the Hyderabad study and a study of Pima Indians also have concluded that DR is common among males. In our study $18 \%$ of patients had bilateral involvement, though the severity was asymmetrical in some patients. $63 \%$ of patients had unilateral involvement. Although, age is not found as a confounding factor as the Asian Young Diabetes Research (ASDIAB) study diabetic subjects who are young were recruited in several Asian countries and they showed less prevalence of DR among Indians in comparison with other Asian groups. Indirect ophthalmoscopy has been used as a standard technique as described by Dandona et al in a study. The sensitivity and specificity of indirect ophthalmoscopy for detecting any retinopathy was $82 \%$ and $95 \%$ respectively. One may speculate that diabetes-associated changes in the trabeculum is related to decreased aqueous outflow. In the Wisconsin Epidemiologic study of Diabetic Retinopathy, approximately $8 \%$ of people with older-one diabetes had intraocular pressures greater than $21 \mathrm{mmHg}$ compared with approximately $3 \%$ in a non-diabetic comparison group of slightly older age. There may be an effect of diabetes on the optic nerve. One can postulate that the optic nerve of people with diabetes may be more susceptible to destructive effects of intraocular pressure. This may exacerbate an increased risk of glaucoma that accompanies aging. Rema et al reported that 1.7-fold increase in risk of DR is seen in subjects who have $2 \%$ increase in $\mathrm{HbA1c}$. The important risk factor for diabetes is the blood HbA1c. Wong et al reported DR risk increases 1-21-fold for every $1 \%$ increase of HbA1c. These observations were confirmed by our study and have showed that a raised blood HbA1c concentration was independently associated with an increased DR prevalence.

\section{Summary}

400 eyes of 200 patients were studied over a period of one year. The predominantly affected group was aged between 40 and $50(42.5 \%)$. The male: female ratio was 2.1 : 1 . A majority of patients had visual acuity between $6 / 9$ and $6 / 18$ on first presentation (43.5\%). Of them, $49.5 \%$ of patients had positive family history. $43 \%$ of the patients were exposed to risk factors like smoking, alcohol and anaemia. $18 \%$ of the patients had bilateral diabetic retinopathy. Of the 400 eyes evaluated 292 eyes had NPDR and 32 had PDR, while 76 had no features of diabetic retinopathy. Among the NPDR majority (135 eyes) fell under moderate NPDR. Of the 200 patients, 18 had PDR at the time of presentation. $18 \%$ of the patients had POAG during the initial presentation. Among the DR patient levels of glycosylated haemoglobin level (HbA1c), more than $7 \mathrm{mmol} / \mathrm{L}$ when compared to patients without DR. This indicated patients would have been having longer duration of DM unnoticed.

\section{CONCLUSION}

Incidence of DR is common among middle-aged working population. Both eyes were usually affected, though asymmetrically. Detailed fundus examination and FFA in selected cases are important in diagnosing the type and severity of diabetic retinopathy. In conclusion, DR including sight threatening complications were found at the time of diagnosis of diabetes mellitus type II. Treatment can help, but this condition cannot be cured. Regular ophthalmological evaluation of fundus is mandatory to detect diabetic retinopathy in early stages in new cases of DM. Early diagnosis of and treatment of DR helps to stabilise the visual acuity and prevent further loss. Diagnosis of complications of DR at the earliest helps to control progression of PDR. Increased awareness of the ophthalmological complication in diabetes is necessary in the society to prevent unnecessary visual morbidity in diabetic patients. So, it is important to take action before one can notice any eye problem. 


\section{REFERENCES}

[1] Klein R, Klein BE, Moss SE. Visual impairment in diabetes. Ophthalmology 1984;91(1):1-9.

[2] Mohan V, Ramachandran A, Snehalatha C, et al. High prevalence of Maturity Onset Diabetes of the Young (MODY) among Indians. Diabetes Care 1985;8(4): 371-4.

[3] Joshi SR. Metabolic syndrome: emerging clusters of the Indian phenotype. J Assoc Physicians India 2003;51:445-6.

[4] Viswanathan M, Mohan V, Snehalatha C, et al. High prevalence of type 2 (non-insulin-dependent) diabetes among the offspring of conjugal type 2 diabetic parents in India. Diabetologia 1985;28(12):907-10.

[5] Mohan V, Shanthirani CS, Deepa R. Glucose intolerance (diabetes and IGT) in a selected South Indian population with special reference to family history, obesity and life style factors: The Chennai Urban Population Study (CUPS 14). J Assoc Physicians India 2003;51:771-7.

[6] Dandona L, Dandona R, Naduvilath TJ, et al. Population based assessment of diabetic retinopathy in an urban population in southern India. $\mathrm{Br} \mathrm{J}$ Ophthal 1999;83(8):937-40.

[7] Connolly V, Unwin N, Sherriff $P$, et al. Diabetes prevalence, socioeconomic status: a population based study showing increased prevalence of type 2 diabetes mellitus in the deprived areas. J Epidemiol Commun Health 2000;54(3):173-7.
[8] Vijay V, Snehalatha C, Shina K, et al. Familial aggregation of diabetic kidney disease in type 2 diabetes in south India. Diabetes Res Clin Pract 1999;43(3):167-71.

[9] Wang WQ, Tai-Pang LP, Lam KS. Changing prevalence of retinopathy in newly diagnosed non-insulin dependent diabetes mellitus patients in Hong Kong. Diabetes Res Clin Pract 1998;39(3):185-91.

[10] Diabetes Control and Complications Trial Research Group. Effect of pregnancy on microvascular complications in the diabetes control and complications trial. The Diabetes Control and Complications Trial Research Group. Diabetes Care 2000;23(8):1084-91.

[11] Singh R, Gupta V, Gupta A, et al. Spontaneous closure of microaneurysms in diabetic retinopathy with treatment of co-existing anaemia. Br J Ophthalmol 2005;89(2):248-9.

[12] Deepa M, Pradeepa R, Rema M, et al. The Chennai Urban Rural Epidemiology Study (CURES) - study design and methodology (urban component) (CURES 1). J Assoc Physicians India 2003;51:863-70. 